\title{
Issues with Human Bioavailability Determinations of Bioactive Curcumin
}

\author{
SJ Stohs*1 and SD Ray ${ }^{2}$ \\ ${ }^{1}$ School of Pharmacy and Health Professions, USA \\ ${ }^{2}$ Department of Pharmaceutical and Biomedical Sciences, USA
}

Received: 㱕: December 18, 2018; Published: 鴊: January 02, 2019

*Corresponding author: SJ Stohs, School of Pharmacy and Health Professions, USA

\begin{abstract}
The health benefits of curcumin which is extracted from turmeric (Curcuma longa) are well known. However, curcumin is poorly absorbed in the gastrointestinal tract and undergoes rapid metabolism to inactive forms. The free form of curcumin is more bioactive than its conjugates. Various formulations have been developed to increase curcumin bioavailability. Most curcumin pharmacokinetic studies measure and report total (free plus conjugated) curcumin, not free, bioactive curcumin as a result of enzymatic hydrolysis of plasma samples prior to extraction and analysis. Hydrolysis results in approximately a 10-fold over-estimation of the amount of total curcuminoids in plasma and greater than a 10-fold over-estimation of free, bioactive curcumin, therefore producing a misrepresentation of the results. As a consequence, caution is warranted in interpreting published pharmacokinetic results and claims involving curcumin products.
\end{abstract}

Keywords: Curcumin; Conjugates; Enzymatic hydrolysis; Bioactive forms

\section{Introduction}

Curcumin is the active polyphenolic constituent in turmeric from the rhizomes of Curcuma longa, and exhibits anti-inflammatory, antioxidant, metabolism regulating, chemoprotective, immunomodulating, antibacterial, antiviral, anti-fungal, antineoplastic, and anti-depressant properties [1-11]. However, unformulated [regular] curcumin is poorly absorbed and exhibits poor bioavailability, limiting its effects and usefulness. Therefore, various formulations have been developed to enhance curcumin bioavailability, including formulations with micelles, liposomes, interaction with macromolecules such as gelatin and various polysaccharides, and nano-particulate preparations including nano-emulsions, nanomicelles, nano-gel, dendrimers, polymers, conjugates and solid dispersions [12,13]

\section{Curcumin Metabolism}

Orally consumed curcumin is rapidly conjugated in the small intestine, liver and kidneys to curcumin glucuronide and curcumin sulfate which undergo rapid excretion in the urine and feces [4-7,11-16]. Curcumin occurs in the blood primarily as these physiologically and pharmacologically inactive conjugates with relatively little free, bioactive curcumin. Curcumin also undergoes extensive metabolic reduction to dihydrocurcumin, tetrahydro curcumin and hexahydro curcumin by intestinal microorganisms [5,11-17]. However, these metabolites also undergo conjugation, converting them into physiologically inactive constituents that are excreted in the urine and feces [5,11-17]. Curcumin is more physiologically active as compared to its conjugated forms, and therefore free curcumin reflects its bio-efficacy as compared to conjugated metabolites [5,11-14]. Pharmacokinetic studies have been conducted with various curcumin formulations. The major pharmacokinetic index used for determining extent of absorption of various curcumin products is a plot of blood plasma concentration of the active constituent(s) against time, yielding the area under the curve (AUC). Data from pharmacokinetic studies of various products can be compared by normalization of the results on the basis AUC/mg curcumin administered.

\section{Enzymatic Hydrolysis}

With few exceptions [13,18,19], plasma samples are routinely subjected to enzymatic hydrolysis with $\beta$-glucuronidase and sulfatase to yield total curcumin [20-32]. Therefore, most pharmacokinetic studies involving curcumin formulations have not demonstrated an increase in free, bioactive curcumin in the blood. Curcumin glucuronide and curcumin sulfate are the primary, physiologically inactive conjugates of curcumin. Therefore, the results do not provide information regarding the potential pharmacokinetic benefits of the formulations with respect to an increase in free, bioactive curcumin. When plasma 
samples are directly extracted without hydrolysis, free curcumin, curcumin glucuronide and curcumin sulfate are detected. Extraction following enzymatic hydrolysis results in the detection of curcumin, tetrahydro curcumin, desmethoxycurcumin and bisdesmethoxycurcumin. Total curcuminoids detected in plasma following hydrolysis increase by a factor of approximately 10 -fold or more as compared to direct extraction without hydrolysis.

In a pilot study, free curcumin in plasma after the administration of a liquid droplet nano micellar formulation (BioCurc $®$ ) represented approximately $15-20 \%$ of the total curcuminoids detected in plasma following direct solvent extraction without enzymatic hydrolysis, while free curcumin after hydrolysis of the plasma samples constituted approximately $25-30 \%$ of the total curcuminoids. Therefore, curcumin content after hydrolysis may not directly correlate with free curcumin in the plasma, with the curcumin content after hydrolysis being as much as 14-fold higher than the free curcumin content determined without hydrolysis. Unfortunately, the effect of hydrolysis is not discussed or considered in most pharmacokinetic studies involving curcumin. Biologically inactive curcumin glucuronide constitutes approximately $75 \%$ of the directly extracted curcuminoids without enzymatic hydrolysis and analyzed by high performance liquid chromatography and tandem mass spectrometry. Tetrahydorcurcumin constitutes over $60 \%$ of the total curcuminoids extracted from plasma after enzymatic hydrolysis, while no free, bioactive tetrahydro curcumin was detected in the plasma samples extracted without hydrolysis.

\section{Summary and Conclusion}

Pharmacokinetic studies with almost all commercial formulations have used enzymatic hydrolysis to free conjugated curcumin prior to analysis. It is not known how these various formulations affect the amount of free curcumin in plasma as compared to the total amount that is reported (free plus conjugated form). Enzymatic hydrolysis of plasma samples prior to solvent extraction may result in at least a 10 -fold over-estimation of the amount of free, bioactive curcumin, thus resulting in exaggerations of the efficacy of the formulations. Conjugates of curcumin cannot be compared to the actions of free curcumin. Enzymatic hydrolysis of plasma samples does not provide an accurate reflection of the plasma levels of free, bioactive curcumin, its bio-efficacy or therapeutic potential.

\section{Conflict of Interest}

S.D.R. has no perceived conflict of interest to report. S.J.S. has served as a consultant for Boston Biopharm Inc.

\section{References}

1. Amalraj A, Pius A, Gopi S, Gopi S (2017) Biological activities of curcuminoids, other molecules from turmeric and their derivatives-a review. J Trad Compl Med 7: 205-233.

2. Rahmani AH, Alsahli MA, Aly SM, Khan MA, Aldebasi YH (2018) Role of curcumin in disease prevention and treatment. Adv Biomed Res 7: 38.

3. Ak T, Gülçin I (2008) Antioxidant and radical scavenging properties of curcumin. Chem Biol Interact 174(1): 27-37.

4. Prasad S, Tyagi AK, Aggarwal BB (2014) Recent developments in delivery, bioavailability, absorption and metabolism of curcumin: the golden pigment from the golden spice. Cancer Res Treat 46(1): 2-18.
5. Kocaadam B, Sanlier N (2017) Curcumin, an active component of turmeric (Curcuma longa), and its effects on health. Crit Rev Food Sci Nutr 57(13): 2889-2895.

6. Kunnumakkara AB, Bordoloi D, Padmavathi G, Monisha J, Roy NK, et al. (2017) Curcumin, the golden nutraceutical: multitargeting for multiple chronic diseases. Br J Pharmacol 174(11): 1325-1348.

7. Pulido Moran M, Moreno Fernandez J, Ramirez Tortosa C, Ramirez Tortosa CM (2016) Curcumin and health. Molecules 21(3): 264.

8. Kotecha R, Takami A, Espinoza JL (2016) Dietary phytochemicals and cancer chemoprevention: a review of the clinical evidence. Oncotarget 7(32): 52517-52529.

9. Huminiecki L, Horbanczzuk J, Alanasov AG (2017) The functional genome studies of curcumin. Semin Cancer Biol 46: 107-118.

10. Fan X, Zhang C, Liu DB, Yan J, Liang HP (2013) The clinical applications of curcumin: current state and the future. Curr Pharm Des 19(11): 20112031.

11. Jurenka JS (2009) Anti-inflammatory properties of curcumin, a major constituent of Curcuma longa: A review of preclinical and clinical research. Alt Med Rev 14(2): 141-153.

12. Douglass BJ, Clouatre DL (2015) Beyond yellow curry: assessing commercial curcumin absorption techniques. J Am Coll Nutr 34(4): 347358.

13. Stohs SJ, Ji J, Bucci LR, Preus RG (2018) A comparative pharmacokinetic assessment of a novel highly bioavailable curcumin formulation with 95 $\%$ curcumin: a randomized, double-blind, cross-over study. J Am Coll Nutr 37(1): 51-59.

14. Pan MH, Huang TM, Lin JK (1999) Biotransformation of curcumin through reduction and glucuronidation in mice. Drug Metab Dispos 27(4): 486-494.

15. Vareed SK, Kakarala M, Ruffin MT, Crowell JA, Normolle DP, et al. (2008) Pharmacokinetics of curcumin conjugate metabolites in healthy human subjects. Cancer Epidemiol Biomarkers Prev 17(6): 1411-1417.

16. Janjun J, Wyganowska Swiatkowska M, Detttlaff K, Jelinska A, Surdacka A, et al. (2016) Determining whether curcumin degradation/condensation is actually bioactivation (Review). Int J Mol Med 37(5): 1151-1158.

17. Hassaninasab A, Hashimoto Y, Tomita Yokotani K, Kobayashi M (2011) Discovery of the curcumin metabolic pathway involving a unique enzyme in an intestinal microorganism. PNAS 108(16): 6615-6620.

18. Gopi S, Jacob J, Varma K, Jude S, Amalraj A, et al. (2017) Comparative Oral Absorption of Curcumin in a Natural Turmeric Matrix with Two Other Curcumin Formulations. Phytother. Res 31(12): 1883-1891.

19. Gota VS, Maru GB, Soni TG, Gandhi TR, Kochar N, et al. (2010) Safety and pharmacokinetics of a solid lipid curcumin particle formulation in osteosarcoma patients and healthy volunteers. Agric Food Chem 58(4): 2095-2099.

20. Antony B, Merina B, Iyer VS, Judy N, Lennartz K, et al. (2008) A pilot cross-over study to evaluate human oral bioavailability of BCM- $95^{\circledR} \mathrm{CG}$ (Biocurcumax ${ }^{\mathrm{TM}}$ ), a novel bioenhanced preparation of curcumin. Ind J Pharm Sci 70(4): 445-449.

21. Purpura M, Lowrey RP, Wilson JM, Mannan H, Munch G, et al. (2018) Analysis of different innovative formulations of curcumin for improved relative oral bioavailability in human subjects. Eur J Nutr 57(3): 929938.

22. Kumar D, Della J, Subash PS, Maliakkal A, Johannah NM, et al. (2016) Enhanced bioavailability and relative distribution of free (unconjugated) curcuminoids following oral administration of a food-grade formulation with fenugreek dietary fibre: a randomized double-blind crossover study. J Funct Foods 22: 478-587.

23. Sasaki H, Sunagawa Y, Takahashi K, Imaizumi A, Fukuda H, et al. (2011) Innovative preparation of curcumin for improved oral bioavailability. Biol. Pharm Bull 34(5): 660-665. 
24. Kanai M, Imaizumi A, Otsuka Y, Sasaki H, Hashiguchi M, et al. (2012) Dose-escalation and pharmacokinetic study of nanoparticle curcumin a potential anticancer agent with improved bioavailability, in healthy human volunteers. Cancer Chemother Pharmacol 69(1): 65-70.

25. Kanai M, Otsuka Y, Otsuka K, Sato M, Nishimura T, et al. (2013) A phase I study investigation the safety and pharmacokinetics of highly bioavailable curcumin (Theracurmin) in cancer patients. Cancer Chemother Pharmacol 71(6): 1521-1539.

26. Asher GN, Xie Y, Moaddel R, Sanghvi M, Sossou KSS, et al. (2017) Randomized pharmacokinetic crossover study comparing 2 curcumin preparations in plasma and rectal tissue of healthy human volunteers. J Clin Pharmacol 57(2): 185-191.

27. Sunagawa Y, Hirano S, Katanaska Y, Miyazaki Y, Funamoto M, et al. (2015) Colloidal submicron-particle curcumin exhibits high absorption efficiency: a double-blind, 3-way crossover study. J Nutr Sci Vitaminol 61(1): 37-44.

\section{ISSN: 2574-1241}

DOI: $10.26717 / B J S T R .2019 .12 .002289$

SJ Stohs. Biomed J Sci \& Tech Res

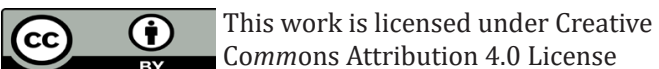

Submission Link: https://biomedres.us/submit-manuscript.php
28. Morimoto T, Sunagawa Y, Katanassaka Y, Hiraon S, Namiki M, et al. (2013) Drinkable preparation of Theracurmin exhibits high absorption efficiency-A single-dose, double-blind, 4-way crossover study. Biol Pharm Bull 36(11): 1708-1714.

29. Jager R, Lowrey RP, Calvanese AV, Joy JM, Purpura M, et al. (2014) Comparative absorption of curcumin formulations. Nutr J 13: 11.

30. Cuomo J, Appendino G, Dern AS, Schneider E, McKinnon TP, et al. (2011) Comparative absorption of a standardized curcuminoid mixture and its lecithin formulation. J Nat Prod 74(4): 664-669.

31. Madhavi D, Kagan D (2014) Bioavailability of a sustained release formulation of curcumin. Integr Med 13(3): 24-30.

32. Briskey D, Sax A, Mallard AR, Rao A (2018) Increased bioavailability of curcumin using a novel dispersion technology system (LipiSperse ${ }^{\circledR}$ ). Eur J Nutr.

$\begin{array}{ll}\text { BIOMEDICAL } & \text { Assets of Publishing with us } \\ \text { RESEARCHES } & \text { - Global archiving of articles } \\ \text { - Immediate, unrestricted online access }\end{array}$

